\title{
The Composition of the Market Portfolio and Real Estate Investment Performance
}

\author{
Crocker H. Liu, New York University \\ David J. Hartzell, University of North Carolina \\ Terry V. Grissom, Texas A\&M \\ Wylie Greig, The RREEF Funds
}

\begin{abstract}
This study investigates whether the composition of the market portfolio leads to different inferences on real estate performance. As a point of departure, this paper first explores whether the omission of assets in a market proxy leads to a biased measurement of investment performance. The study finds that ranking investment performance is not meaningless even though investment performance is inaccurately measured. Furthermore, the composition of the market proxy does not necessarily lead to different inferences on real estate investment performance although superior real estate investment performance arises from the omitted asset phenomenon and also from smoothing bias in general.
\end{abstract}

\section{Introduction}

Controversy exists as to whether investment performance is sensitive to the composition of the market portfolio. The central issue in this controversy involves ascertaining if an asset market other than the asset market within which an asset trades influences the return on that asset. Although some performance studies have included real estate in the market proxy to evaluate stock returns, little research exists on the relevance of omitted asset markets to real estate investment performance.

The purpose of this study therefore is to determine whether the composition of the market portfolio leads to different inferences on the performance of either direct real estate investment or indirect participation in real estate through real estate securities. Another goal of this research is to ascertain if the measure of real estate investment performance is stationary over different economic environments given that positive excess returns exist. As a prelude to this investigation, this paper first explores whether the omission of assets in a market proxy leads to a biased measurement of investment performance. If an index with missing assets inaccurately measures investment performance, then the ranking based on that performance might not convey useful information. 
A distinctive feature of this study is that cross-equation linear restrictions are used to test whether the performance measurement bias that arises from a misspecified market portfolio matters. Although a serious bias is found to arise with respect to the measurement of market risk, both inflation risk and the performance measure are invariant to various market portfolio specifications across all asset classes. This result implies that ranking investment performance is not necessarily meaningless even though investment performance is inaccurately measured.

In examining superior investment performance arising from the omission of assets in a market proxy, this study not only explores the robustness of the S\&P 500 as the portfolio performance benchmark but also examines the consequences of including a commercial real estate return series based on imputed sale prices in lieu of an appraisal-based return series in the market proxy. The robustness of the S\&P 500 with respect to real estate has not been examined thus far although most researchers acknowledge that this index is too "narrow" because it consists only of stocks with large market capitalizations. Interestingly, fewer assets exhibit superior performance when the S\&P 500 is used as the benchmark portfolio compared to all other proxies except for a US market wealth portfolio which contains commercial real estate returns based on imputed sale prices (denoted USMI1). In addition, the performance rankings based on the S\&P 500 are similar to those for the USMI1. In contrast, more assets have positive excess returns when a US market wealth index that includes appraisal-based real estate returns (denoted USMI2) is employed relative to the S\&P 500. However, the use of the USMI2 together with a zero beta version of our performance measure results in fewer properties with appraisal-based returns having superior investment performance relative to either the S\&P 500 or the USMI1. These consequences of real estate investment performance with respect to the two alternative commercial real estate return series represent another unique feature of this study.

An additional feature of this study is an examination of the stationarity of the performance measure with respect to real estate. This examination reveals that the investment performance measure is not stationary over economic subperiods even after adjusting for inflation. The stationarity of the performance measure however differs with respect to each asset class. A large portion of commercial properties whose returns are appraisal-based exhibit variations in investment performance over the high inflation and low inflation subperiods. In contrast, few equity real estate investment trusts (EREITs), common stocks, and commercial properties whose returns are computed with imputed sale prices have nonstationary investment performance.

The remainder of the paper proceeds as follows. The second section offers a review of the omitted asset controversy relative to the evaluation of investment performance. The third section gives 
a summary of data sources used and explains the construction of market indexes. The methodology is discussed in the fourth section. Results of alternative index specifications are given in the fifth section, while the sixth section concludes the study.

\section{Brief Literature Review}

Controversy exists as to whether the investment performance of an asset is sensitive to the composition of the market proxy. Both Mayers [14] and Roll [17] demonstrate that no asset should exhibit positive excess returns in theory when the market proxy includes all asset markets. On the other hand, both Fama and Schwert [4] and Stambaugh [19] empirically show that omitted asset markets do not pose a problem in estimating common stock returns. Brown and Brown [1] in contrast find that the composition of the market portfolio does result in different inferences on investment performance for the same set of mutual funds.

To understand this controversy, a decomposition of the true market portfolio into asset submarkets is necessary. Mathematically, the traditional Sharpe-Lintner-Mossin CAPM is

$$
E\left(\tilde{R}_{j}\right)-r_{f}=\lambda M \operatorname{cov}\left(\tilde{R}_{j}, \tilde{R}_{M}\right)
$$

where $M$ is the aggregate market value of all assets, and $\lambda$ is the risk-aversion factor. If $M$, is defined as the aggregate market value of a security market proxy such as the S\&P 500, then (1) is alternatively expressed as

(2)

$$
E\left(\tilde{R}_{j}\right)-r_{f}=\lambda M_{s} \operatorname{cov}\left(\tilde{R}_{j}, \tilde{R}_{M_{s}}\right)+\left[\lambda \sum_{i \neq s}^{\mathrm{i}} M_{i} \operatorname{cov}\left(\tilde{R}_{j}, \tilde{R}_{M_{i}}\right]\right.
$$

where the term in brackets [.] or [...] represents the aggregate return from all omitted asset markets and $i$ is the ith asset market. If the covariance of the return on asset; with the return on the ith asset submarket is zero where $i$ does not represent the security submarket $\mathrm{S}$, then (2) degenerates to a CAPM with a security market proxy

$$
E\left(\tilde{R}_{j}\right)-r_{f}=\lambda M_{s} \operatorname{cov}\left(\tilde{R}_{j}, \tilde{R}_{M s}\right)
$$

The key issue in this controversy therefore is not whether the true market portfolio is required but whether the term in brackets in (2) is significantly different from zero for the $j$ th asset class. 
None of the aforementioned studies investigates whether the omitted real estate market is important with respect to real estate returns although an implication exists that the market index chosen should reflect the relevant universe of the sample of securities tested. These studies also do not address either the extent to which the measurement of investment performance is biased if the market index excludes certain assets or the consequence of this bias with respect to performance ranking.

Brueggeman, Chen and Thibodeau [2] and Ibbotson and Siegel [9] find evidence that positive excess returns exist for commercial real estate even after various types of real estate are included in the market portfolio and an adjustment is made for inflation. However, the use of appraised data over a primarily inflationary environment raises the question of whether excess returns arise from the time period chosen, appraisal-induced biases, or both effects. Smith and Shulman [18] suggest that the time period chosen might bias the investment performance results in favor of real estate. Their major finding is that neither equity real estate investment trusts (REITs) nor stocks dominates all economic subperiods periods examined. However, none of the real estate performance studies formally test whether the measures of performance and risk remain stationary across different economic subperiods in an analogous fashion to the stock performance studies of Fabozzi and Francis [5] and Kon and Jen [12]. Hoag [7] and Giliberto [6] show that appraisal data might also offer a rationale for abnormal returns because smoothing not only understates risk but also overstates the true return.

The present study attempts to rectify the aforementioned concerns through the use of real estate returns computed with imputed sale prices. Imputed real estate returns are used to construct a market index and this index is compared to one that includes appraisal-based real estate returns. Moreover, individual equity REITs are also used in addition to commercial properties whose returns are appraisal based and commercial real estate whose returns are computed with imputed sale prices to investigate positive performance bias.

\section{Data}

\section{Asset Return Series}

Quarterly holding period returns (HPR) are computed for commercial nonfarm real estate returns, equity REITs, and common stock industry groups for the period from June 1978 through September 1986. The availability of time-series data for commercial nonfarm real estate dictates the time interval evaluated. Fortunately, high inflation characterizes the period from the second quarter of 1978 to the end of 1981 while low inflation is associated with the post-1981 period. Thus, the positive 
rising inflation (and thus possibly real estate return) bias prevalent in most earlier real estate investment performance studies is absent in the present study. The sources of data that underlie the return calculations for each asset category follow:

Commercial Nonfarm Real Estate: Commercial nonfarm real estate returns are constructed from several sources. The first surce consists of twenty-two quarterly return indices from the National Council of Real Estate Investment Fiduciaries (NCREIF) in conjunction with the Frank Russell Company (FRC). The total FRC index is also used in the current study. The FRC indexes are value-weighted appraisal indexes with all properties in the index unlevered.

Commercial real estate returns are also computed with imputed sale prices. To impute prices, quarterly net operating income (NOI) per square foot for nine regional property types are obtained from a large, diversified commingled real estate fund (CREF). Quarterly cap rates for these regional property types gathered from the American Council of Life Insurance Companies (ACLI) publication Mortgage Commitments on Multifamily and Nonresidential Properties are divided into the respective NOI to yield imputed prices. ${ }^{1}$

Equity Real Estate Investment Trusts (EREIT): Eighteen EREITs that possess continuous prices and dividends over the study period are evaluated in the current study. Quarterly prices, dividends, and the number of shares outstanding for each EREIT are extracted from the COMPUSTAT tapes and Standard and Poor's Security Owner's Stock Guide.

Stocks: Quarterly price and dividend information on fifty-eight industry groups are compiled from issues of Standard and Poor's Analyst Handbook, Monthly Supplement. ${ }^{2}$

Further elaboration on the construction and limitations of holding period returns for each asset are found in Liu [13]. Appendix A lists the specific assets associated with each general asset category.

\footnotetext{
${ }^{1}$ The capitalization rate is defined as the net operating income for a property divided by its selling price. The prices that result from dividing net operating income by the capitalization rate do not represent specific market transactions. However, the cap rates are computed from specific market transactions and thus provide an indicator of market-wide variations in sale prices. This process is analogous to backing out stock prices given information on the dividend yield and the amount of the dividend in each period. For a recent study that has used this technique, see Nourse 116].

The use of ACLI cap rates is not without problems. Critics charge that inaccuracies exist in the cap rates reported since some organizations who report cap rates to the ACLI do not carefully verify their figures. This leads to reporting errors in individual cap rates. However, these reporting errors are minimized to some extent since the ACLI computes and reports an average of the cap rates for any particular quarter. The number of properties reported sold per quarter for the office, industrial and retail property categories exceeds twenty on average but for apartments and hotels the numbers are often below three.

${ }^{2}$ All industries with continuous price and dividend data on a quarterly basis over the study period are used. The industry indices are value weighted and derived in an identical fashion to the S\&P 500 index.
} 


\section{The Market Indexes}

Investment performance of the preceding return series is investigated relative to six valueweighted market proxies. The first market index is the S\&P 500, which represents a portfolio of wellcapitalized (large) firms. Market proxy 2 is the Media General Composite Index (MGCl) reported in the Media General Financial Weekly. This index includes stocks of small capitalized firms in addition to stocks of large capitalized firms. ${ }^{3}$ The third index, known as the security market index (SMI), combines the $\mathrm{MGCl}$ with corporate bonds, government bonds, mortgage-backed bonds, and cash equivalents. Index 4, hereafter referred to as the US market index (USMI), adds commercial real estate, farms, and single-family homes to the SMI proxy. A value-weighted return index constructed from returns imputed from the ACLI data is used for the commercial real estate component. As an alternative to imputed commercial real estate returns, the value-weighted FRC index is used with the resulting market proxy denoted USMI2. Alternative versions of the USMI index are used to explore the impact that the inclusion of appraisal-based returns in the market proxy has on investment performance. The market values used to construct the USMI portfolio weights are discussed in Appendix B. ${ }^{4}$ The sixth index is the investable capital market (ICM) obtained from First Chicago Investment Advisors. The ICM index consists of nine asset classes - large cap equity, small cap equity, international equity, venture capital, domestic bonds, international bonds, nondollar bonds, cash equivalents, and commercial properties - with the commercial nonfarm real estate component based on appraised values The index is calculated as the share price of common shares multiplied by the number of shares outstanding for all corporations traded on the NYSE. ASE and NASDAQ. Rights, preferred stock and when issued stocks are excluded. The index is adjusted for all stock splits, stock dividends, delistings, suspensions, or halts of trading or dividend distributions through a recalculation of the base market value. Ibbotson and Fall [8] use the market value of the $\mathrm{MGCl}$ as a proxy for the aggregate value of all stocks to construct a US market index. from properties in a CREF portfolio. The sum of the asset submarkets does not represent the "true" US

\footnotetext{
${ }^{3}$ The index is calculated as the share price of common shares multiplied by the number of shares outstanding for all corporations traded on the NYSE. ASE and NASDAQ. Rights, preferred stock and when issued stocks are excluded. The index is adjusted for all stock splits, stock dividends, delistings, suspensions, or halts of trading or dividend distributions through a recalculation of the base market value. Ibbotson and Fall [8] use the market value of the $\mathrm{MGCl}$ as a proxy for the aggregate value of all stocks to construct a US market index.

${ }^{4}$ Stocks comprise $23 \%$ of the USMI proxy and range from $22 \%$ to $24 \%$. Bonds account for an additional $13 \%$ of the USMI index although this weight varies from $10 \%$ to $15 \%$. Cash equivalents comprise another $7 \%$ to $8 \%$ of the index while all types of real estate combined represent over $50 \%$ of the US market wealth. Single-family homes represent the largest of the three property types and accounts for $30 \%$ of the estimated US market wealth. An additional $17 \%$ of the USMI consists of commercial nonfarm real estate while the remaining $10 \%$ of aggregate wealth consists of farm real estate.
} 
market portfolio because assets such as human capital and consumer durables are omitted. A possibility also exists that some assets are overstated. ${ }^{5}$ Despite these shortcomings, the asset classes included comprise the most liquid and identifiable components of investable capital wealth. The study consequently assumes that the asset categories chosen are a reasonable representation of the investment marketplace.

\section{Methodology}

The Brueggeman, Chen and Thibodeau (BCT) [1984] modification of the Jensen [10] performance measure is used to test the extent to which superior investment performance of commercial, nonfarm real estate is sensitive to the composition of the market portfolio. This performance measure is based on the capital asset pricing model under uncertain inflation (CAPMUI) and has the following form:

(4)

$\tilde{R}_{j t}-r_{f t}=a_{j}+\beta_{j 1}\left[\tilde{R}_{M t}-r_{f t}\right]+\beta_{j 2}\left[\tilde{\pi}_{t}-r_{f t}\right]+\tilde{\varepsilon}_{j t}$

where $\left(\tilde{R}_{j t}-r_{f t}\right)$ is the excess return on the jth portfolio in period $t,\left(\tilde{R}_{M t}-r_{f t}\right)$ is the excess return on the market portfolio in period $t,\left(\tilde{\pi}_{t}-r_{f t}\right)$ is the excess inflation rate in period $t$, and a-is the modified Jensen measure. A positive (negative) $a_{j}$ implies that portfolio $j$ exhibits a return that exceeds (is lower than) the premiums for expected risk and inflation. As an alternative to equation (4), a zero beta version of the BCT performance measure is also tested given the observation of Stambaugh [19] that different inferences arise from the Sharpe-Lintner version of the CAPM compared with the Black version of the CAPM. The Black version of the BCT performance measure is similar to the BCT index with the return on the zero beta portfolio $\tilde{r}_{z t}$ replacing the risk-free rate $r_{f t}$ in equation (4) as follows: ${ }^{6}$

\footnotetext{
${ }^{5}$ Double counting might arise because multiple financial claims on the same underlying asset are present. Corporations holding common stock of another corporation is one example of this phenomenon. Another example is real estate and real estate mortgages. The current study attempts to avoid the latter type of double counting through using only the total equity value for various property types. Some types of double counting still remain however with the impact of omitted assets unknown.

${ }^{6}$ To calculate the weights associated with the zero beta portfolio, the following quadratic programming problem is solved for:

$$
\operatorname{Min} \sigma_{p}^{2}=x_{2}^{T} V x_{2}
$$$$
\text { subject to } x^{T} V x_{M}=\sigma_{Z M}=0 \text { and } x^{T}{ }_{Z^{l}}=1
$$

where $\sigma_{p}^{2}$ is the variance of the zero beta portfolio, $x_{Z}^{T}$ is the row vector containing the minimum-variance zerobeta portfolio weights, $V$ is the variance-covariance matrix of the returns for all asset classes in the market proxy,
} 
(5)

$$
\tilde{R}_{j t}-\tilde{r}_{z t}=a_{j}+\beta_{j 1}\left[\tilde{R}_{M t}-\tilde{r}_{z t}\right]+\beta_{j 2}\left[\tilde{\pi}_{t}-\tilde{r}_{z t}\right]+\tilde{\varepsilon}_{j t}
$$

Six market proxies are utilized in calculating the BCT performance measure for each asset in equation (4) while four indexes are used to compute the zero beta version of the BCT excess return index given in equation (6). ${ }^{7}$ In estimating the parameters associated with each respective model, a series of cross-equation linear restrictions are tested to investigate the possible bias in estimates of systematic risks $\left(\beta_{j 1}\right.$ and $\left.\beta_{j 2}\right)$ using different market indices and to check whether the performance measures $\left(\tilde{a}_{j}\right)$ are compatible among different models with different market proxies. A test of crossequation linear restrictions is necessary because estimates of both alphas and betas are biased if a market index that has missing assets represents a misspecification of the true model. Consequently, the ranking of alphas generated from the six market proxies might not convey any useful information. ${ }^{8}$ The cross-equation linear restrictions are tested with respect to pairwise comparisons of the same model using different market proxies as follows:

(6)

$$
\tilde{R}_{j t}-r_{f t}=a_{j k}+\beta_{j k 1}\left[\tilde{R}_{M k} t-r_{f t}\right]+\beta_{j k 2}\left[\tilde{\pi}_{t}-r_{f t}\right]+\tilde{\varepsilon}_{j k t} \quad \tilde{R}_{j t}-r_{f t}=a_{j q}+\beta_{j q 1}\left[\tilde{R}_{M q t}-r_{f t}\right]+\beta_{j q 2}\left[\tilde{r}_{t}-r_{f t}\right]+\tilde{\varepsilon}_{j q t}
$$

subject to $a_{j k}=a_{j q}, \beta_{j k 1}=\beta_{j q 1}, \beta_{j k 2}=\beta_{j q 2}$

where market proxies $k$ and $q$ represent two different indexes. An F-test is used to test these crossequation linear restrictions. These cross-equation linear restrictions are tested relative to both the BCT model and the zero beta version of the BCT model. In addition to this, cross-equation linear restrictions are also tested with respect to a BCT model and a zero beta version of a BCT model that recognizes possible economic regime shifts.

The test for economic regime shifts is similar to that used in Fabozzi and Francis [5]. The purpose of this test is to see whether the alphas and betas in the BCT model and the zero beta version of the BCT

\footnotetext{
$x_{M}$ is the column vector of weights in the market proxy, $\sigma_{Z M}$ is the covariance between the return on the market proxy and the zero-beta portfolio and $\iota$ is the unity vector.

7 We were unable to construct zero beta portfolios for the S\&P 500 and the MGCl portfolios because we could not obtain the market weights for each stock in these portfolios.

${ }^{8}$ We thank an anonymous referee for pointing out that if an index with missing assets creates serious problems in accurately measuring investment performance, then the ranking based on alphas does not provide any useful information.
} 
model change with respect to the high inflation and low inflation subperiods. To test for the stability of coefficients relative to the BCT model, equation (4) is modified as follows:

$$
\begin{aligned}
& \tilde{R}_{j t}-r_{f t}=a_{j}^{1}+\left(a^{2}{ }_{j}-a^{1}\right) D_{1}+\beta_{j 1}^{1}\left[\tilde{R}_{M t}-r_{f t}\right]+\left(\beta^{2}{ }_{j 1}-\beta^{1}{ }_{j 1}\right)\left\{D_{1}\left[\tilde{R}_{M t}-r_{f t}\right]\right\} \\
& +\beta^{1}{ }_{j 2}\left[\tilde{\pi}_{t}-r_{f t}\right]+\left(\beta^{2}{ }_{j 2}-\beta^{1}{ }_{j 2}\right)\left\{D_{1}\left[\tilde{\pi}_{t}-r_{f t}\right]+\tilde{\varepsilon}_{j t}\right.
\end{aligned}
$$

where $D_{1}$ is a binary variable that assumes a value of zero in the high inflation environment and a value of unity in the low inflation environment. A similar stability test is constructed for the zero beta version of the BCT model in equation (5). The coefficients $\left(a_{j}^{2}-a_{j}^{1}\right),\left(\beta_{j 1}^{2}-\beta_{j 1}^{1}\right)$, and $\left(\beta_{j 2}^{2}-\beta_{j 2}^{1}\right)$ measure the differential impact of the inflation subperiod on the alphas and betas for the $j$ th asset, where the superscripts 1 and 2 refer to the high and low inflation subperiods respectively. If the alphas and betas for the jth asset differ over the economic subperiods, then these coefficients will be significantly different from zero. Nonzero coefficients suggest that the high inflation and/or low inflation subperiod alter the return distribution of an asset. An F-(Chow) test on the incremental sum of squares computed by advancing from equation (4) to equation (7) is also used to test the hypothesis that the coefficients of both $\left(a_{j}^{2}-a_{j}^{1}\right),\left(\beta_{j 1}^{2}-\beta_{j 1}^{1}\right)$, and $\left(\beta_{j 2}^{2}-\beta_{j 2}^{1}\right)$ are zero. This test complements the T-test on both $\left(a_{j}^{2}-a_{j}^{1}\right)$ and on $\left(\beta_{j 1}^{2}-\beta_{j 1}^{1}\right)$, and $\left(\beta_{j 2}^{2}-\beta_{j 2}^{1}\right)$ because the F-test is a test for the stability of the entire regression relationship. The incremental F-test is necessary in addition to the individual T-tests because it is possible that the T-ratios for each set of coefficients are all insignificant while the F-ratio for the entire set of coefficients is significant (and vice versa).

Assets are ranked in descending order with respect to the BCT performance index and the zero beta version of the BCT excess return measure. Ranking is undertaken only if advancing from a relatively incomplete specification of the market proxy to a more complete specification of the market index does not bias the estimate of alphas. The ranking process consists of first classifying assets into one of three groups with a $5 \%$ level of significance used for the purpose of delineation. This classification scheme is used for each of the six market proxies. The first group consists of all assets that exhibit significantly positive alphas. Assets that significantly underperform the market are placed in the third group, while the second group of assets have similar performance to the market. Assets in the first and third categories are next sorted with respect to alpha in descending order within each group.

\section{Results on Investment Performance}

The composition of the market portfolio does not necessarily lead to different inferences on real estate investment performance even though real estate is excluded from the market index and this 
omission leads to an inaccurate measurement of investment performance. Tables 1 and 2 report the extent of the bias in the estimates of market risk, the risk of uncertain inflation and excess returns that arise from a misspecified market proxy using the BCT model and the zero beta version of the BCT model respectively. The period analyzed is from the second quarter of 1978 to the third quarter of 1986 . Both tables reveal that significant bias exists in the measurement of market risk for all asset classes except the FRC properties when a market portfolio that excludes real estate such as the S\&P 500, MGCl, or SMI is compared with either USMI index in which real estate is the dominant component. An examination of the risk coefficients for each asset indicates that the market risk increases on average when real estate is included in the market proxy. Interestingly however, the measurement bias associated with market risk is also significant for equity REITs and common stocks when either USMI index is compared with the ICM market proxy. This situation arises in part because real estate comprises less than $15 \%$ of the ICM proxy. One plausible reason why the market risk for FRC properties does not exhibit any significant measurement error is that the returns on these assets are subject to smoothing.

\section{TABLE 1}

\section{Test for Impact of Misspecified Market Proxy on Coefficients Using Equation (6)}

\begin{tabular}{|c|c|c|c|c|c|c|c|c|c|}
\hline \multicolumn{10}{|c|}{$\begin{array}{c}5 \% \text { Level of Significance } \\
\text { 1978Q2-1986Q3 }\end{array}$} \\
\hline \multicolumn{2}{|c|}{ Paired Proxies } & \multicolumn{4}{|c|}{$\begin{array}{cc} & \text { Excess Returns Com } \\
\text { EREITS } & \text { STOCKS } \\
\beta_{j+1} \neq \beta_{p=1} & \beta_{j+1} \neq \beta_{i 11}\end{array}$} & $\begin{array}{l}\text { Using } \\
\text { FRC } \\
\beta_{b 1} \\
\text { No. }\end{array}$ & $\begin{array}{l}\text { Riskle } \\
R . E \\
\qquad \beta_{\mathrm{st}} \\
\%\end{array}$ & \multicolumn{2}{|c|}{$\begin{array}{l}{ }^{\prime} \\
\beta_{n 1} \neq \beta_{n 1}\end{array}$} \\
\hline SP500 & $\mathrm{MGCl}$ & 0 & 0 & 0 & 0 & 0 & 0 & 0 & 0 \\
\hline SP500 & SMI & 0 & 0 & 13 & 22.4 & 0 & 0 & 0 & 0 \\
\hline SP500 & USMII & 3 & 16.7 & 36 & 62.1 & 0 & o & 1 & 11.1 \\
\hline SP500 & USMI2 & 6 & 33.3 & 52 & 89.7 & 0 & o & 0 & 0 \\
\hline SP500 & ICM & 0 & 0 & 5 & 8.6 & 0 & 0 & 0 & 0 \\
\hline $\mathrm{MCCl}$ & SMI & 0 & 0 & 14 & 24.1 & 0 & 0 & 0 & 0 \\
\hline $\mathrm{MGCI}$ & USMI1 & 5 & 27.8 & 34 & 58.6 & 0 & o & 2 & 22.2 \\
\hline $\mathrm{MGCl}$ & USMI2 & 6 & 33.3 & 52 & 89.7 & 0 & 0 & 1 & 11.1 \\
\hline $\mathrm{MGCl}$ & ICM & 0 & 0 & 4 & 6.9 & $o$ & 0 & 0 & 0 \\
\hline SMI & USMII & 1 & 5.6 & 11 & 19.0 & 0 & 0 & 1 & 11.1 \\
\hline SMI & USMI2 & 2 & 11.1 & 33 & 56.9 & 0 & 0 & 0 & 0 \\
\hline SMI & ICM & 0 & 0 & 0 & 0 & 0 & 0 & 0 & 0 \\
\hline USMII & USMI 2 & 0 & 0 & 0 & 0 & 0 & 0 & 0 & 0 \\
\hline USMI1 & ICM & 1 & 5.6 & 17 & 29.3 & 0 & 0 & 0 & 0 \\
\hline USMI2 & ICM & 2 & 11.1 & 39 & 67.2 & 0 & 0 & 0 & 0 \\
\hline
\end{tabular}

Legend: No. (\%) refers to the number (percentage) of assets in an asset class for which a misspecification in the market proxy results in a statistically significant bias in the appropriate coefficient. The No. and \% of assets for the $\beta_{k 1} \neq \beta_{q 2}$ and $a_{14} \neq a_{1 q}$ categories are zero for each asset class. 
TABLE 2

\section{Test for Impact of Misspecified Market Proxy on Coefficients Using Zero Beta Version of Equation (6)}

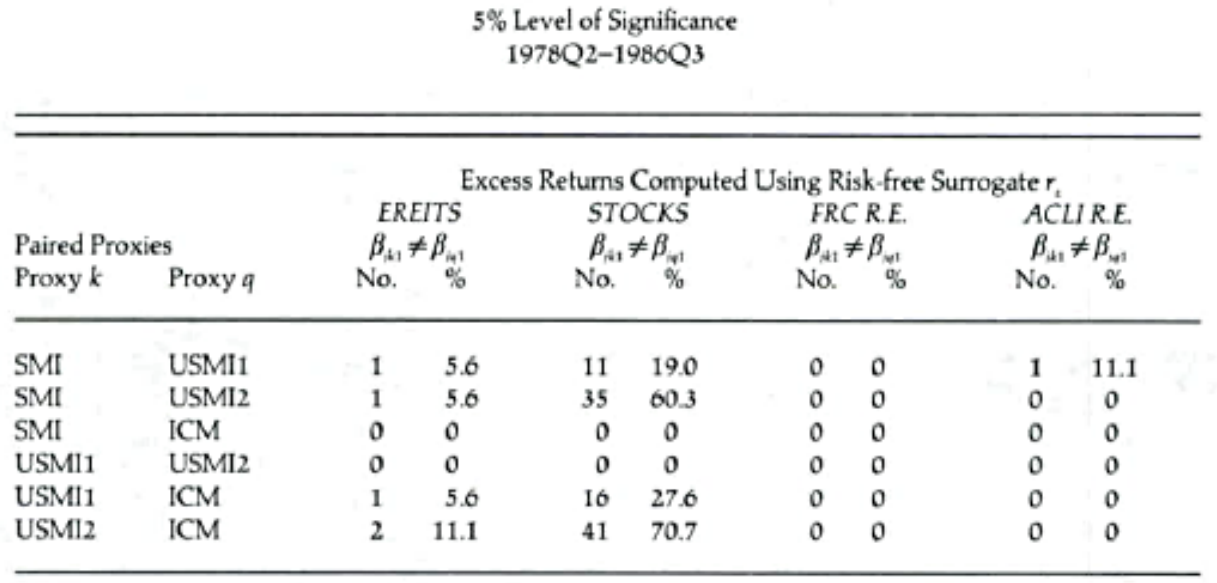

Legend: No. (\%) refers to the number (percentage) of assets in an asset class for which a misspecification in the market proxy results in a statistically significant bias in the appropriate coefficient. The No. and \% of assets for the $\beta_{i 22} \neq \beta_{k 4}$ and $a_{14} \neq a_{14}$ categories are zero for each asset class.

In contrast to the measurement bias associated with the estimate of market risk, the measurement bias that corresponds to both inflation risk and the BCT performance measure is not significant when various market portfolio specifications are compared pairwise using equation (6) across all asset classes. This finding holds regardless of whether the risk-free asset or a risk-free surrogate is used. This result implies that the ranking of investment performance is not necessarily a meaningless exercise even though investment performance is inaccurately measured.

Similar findings obtain when the measurement bias in the coefficients arising from a misspecified market proxy is investigated across economic subperiods using the economic regime shift model in equation (7). Tables 3 and 4 , like 1 and 2, show that significant measurement bias exists only with respect to the estimate of market risk. More specifically, significant measurement bias for the market risk estimate is associated with a greater number of equity REITs, stocks and ACLI properties in a high inflation environment. In contrast, this measurement bias is significant for only one stock hut no EREITs or ACLI properties during a low inflation environment. No significant bias is present on the other hand for the inflation risk estimate or the BCT performance measure given either economic environment. A column of zeros for the $\beta_{j k 2}^{1} \neq \beta_{j q 2}^{1}$ and $B_{2 k} \neq B_{2 q}$ columns in Tables 3 and 4 , which represent the test for measurement bias in inflation risk given high and low inflation subperiods respectively and a column of zeros for the $a_{j k 1}^{1} \neq a_{j q 1}^{1}$ and $A_{k} \neq A_{q}$ columns, which characterize the test for the extent of measurement errors in the BCT performance measurement evidence this. 
TABLE 3

Test for Misspecified Market Proxy's Impact on Coefficients Using Equation (7) to Analyze Economic Subperiods

\begin{tabular}{|c|c|c|c|c|c|c|c|c|c|}
\hline \multicolumn{2}{|c|}{ Paired Proxies } & \multicolumn{2}{|c|}{$\begin{array}{c}\text { EREITS } \\
\beta_{\alpha_{1}} \neq \beta_{k t}\end{array}$} & \multicolumn{2}{|c|}{$\begin{array}{l}\text { STOCKS } \\
\beta_{k 1} \neq \beta_{n 1}\end{array}$} & \multicolumn{2}{|c|}{$\begin{array}{c}F R C R . E \\
\beta_{n 11} \neq \beta_{n: 1}\end{array}$} & \multicolumn{2}{|c|}{$\begin{array}{l}\text { ACLIR.E. } \\
\beta_{j \mathrm{j}} \neq \beta_{k, 1}\end{array}$} \\
\hline SP500 & $\mathrm{MGCl}$ & 0 & 0 & 0 & 0 & 0 & 0 & 0 & 0 \\
\hline SP500 & SMI & 0 & 0 & 0 & 0 & 0 & 0 & 0 & 0 \\
\hline SP500 & USMI1 & 2 & 11.1 & 4 & 6.9 & 0 & 0 & 1 & 11.1 \\
\hline SP500 & USMI2 & 5 & 27.8 & 24 & 41.4 & 0 & 0 & 1 & 11.1 \\
\hline SP500 & ICM & 0 & 0 & 0 & 0 & 0 & 0 & 0 & 0 \\
\hline $\mathrm{MGCI}$ & SMI & 0 & 0 & 0 & 0 & 0 & 0 & 0 & 0 \\
\hline MGCI & USMI1 & 1 & 5.6 & 9 & 15.5 & 0 & 0 & 1 & 11.1 \\
\hline $\mathrm{MGCl}$ & USMI2 & 5 & 27.8 & 28 & 48.3 & 0 & 0 & 1 & 11.1 \\
\hline $\mathrm{MGCl}$ & $1 \mathrm{CM}$ & 0 & 0 & 0 & 0 & 0 & 0 & 0 & 0 \\
\hline SMI & USMI1 & 0 & 0 & 2 & 3.4 & 0 & 0 & 0 & 0 \\
\hline SMI & USMI2 & 3 & 16.7 & 17 & 29.3 & 0 & 0 & 0 & 0 \\
\hline SMI & $\mathrm{ICM}$ & 0 & 0 & 0 & 0 & 0 & 0 & 0 & 0 \\
\hline USMII & USM12 & 0 & 0 & 0 & 0 & 0 & 0 & 0 & 0 \\
\hline USMII & $\mathrm{ICM}$ & 1 & 5.6 & 4 & 6.9 & 0 & 0 & 0 & 0 \\
\hline USMI2 & $\mathrm{ICM}$ & 3 & 16.7 & 21 & 36.2 & $o$ & 0 & 0 & 0 \\
\hline
\end{tabular}

Note: No. $(\%)$ refers to the number (percentage) of assets in an asset class for which a misspecification in the market proxy results in a statistically significant bias in the appropriate coefficient. The No. and $\%$ of assets for all other categories are zero for each asset class with the exception of the $B_{14} \neq B_{14}$ category for

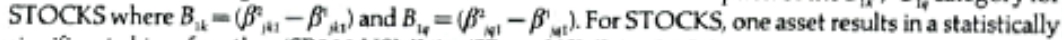
significant bias for the (SP500,USMI1), (SP500,USMI2), (MGC1,USMI1), (MGCI,USMI2), and (USMI2,ICM) paired proxies.

TABLE 4

Test for Impact of Misspecified Market Proxy on Coefficients at $5 \%$ Level of Significance

Zero Beta Version of Equation (7) Is Used to Analyze Economic Subperiods

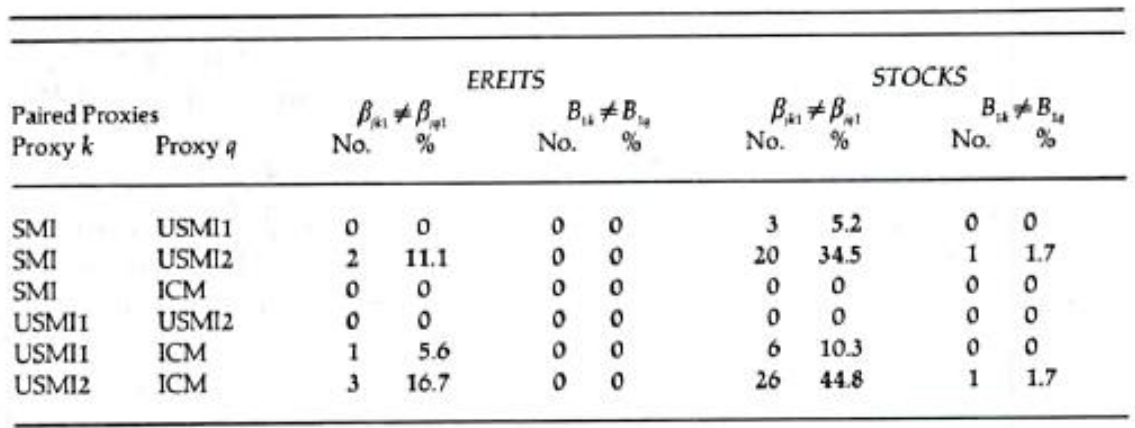

Note: No. $(\%)$ refers to the number (percentage) of assets in an asset class for which a misspecification in the market proxy results in a statistically significant bias in the appropriate coefficient. The No. and $\%$ of assets for all other categories are zero for each asset class except for the $\beta_{k 2} \neq \beta_{142}^{1}$ and $B_{24} \neq B_{24}$ categories for FRC with respect to the (USMI2,ICM) paired proxies. One FRC asset has a significant bias on each coefficient.

Given that the bias associated with the BCT performance measures are not significant, we can now proceed to examine whether a "narrow" market proxy such as the S\&P 500 is robust with respect 
to real estate. The S\&P 500 is narrow in the sense that the index consists only of stocks with large market capitalizations. This does not necessarily imply that the real estate market is not represented because the S\&P 500 includes real estate-related components such as homebuilding. In addition to this, corporations that comprise the S\&P 500 hold approximately two-thirds of all US nonresidential property.

We find that the S\&P 500 is relatively robust with respect to investment performance; fewer assets exhibit superior performance when the S\&P 500 is used as the benchmark portfolio for performance evaluation compared to all other proxies except for the USMI1. Table 5 shows that of the 107 assets examined, only 13 assets (12\%) exhibit superior investment performance using the S\&P 500 as the market proxy. In contrast, the number of assets that possess abnormal returns relative to the MGCI, SMI, USMI2 and ICM indexes are 26, 23, 17 and 18 assets respectively. Only the USMI1 has fewer assets (11 assets) which have excess returns. A look at Table 5 also reveals that the similar rankings exist between the S\&P 500 and USMI1. This finding is in contrast to the implications of Brown and Brown [1] who find that the composition of the index does matter. The discrepancy in the results arises because the S\&P 500 is the initial benchmark portfolio in the current study whereas Brown and Brown use an index similar to the $\mathrm{MGCl}$. This suggests that it is the inclusion of small cap stocks in a market proxy that leads to a greater number of assets having superior investment performance and that the addition of real estate "undoes" this effect.

Of the asset classes in Table 5 that exhibit superior investment performance on each market proxy, the FRC commercial real estate category has more properties with positive excess returns than either equity REITs or common stocks. On the other hand, no ACLI property has a significant BCT performance $a$ on any market proxy. This suggests that smoothing in appraisal-based returns might offer an alternative explanation for excess returns in commercial real estate in lieu of the omitted asset argument. However, an inspection of Table 5 reveals that the omitted asset argument does account for a portion of abnormal returns, especially if a commercial real estate return series based on imputed sale prices is included in the market proxy. For example, all common stock and ACLI properties are correctly priced and only one equity REIT-EastGroup Properties-exhibits superior investment performance relative to the USMI1. Besides this, the number of assets having abnormal returns decreases if the MGCI rather than the S\&P 500 is used as the benchmark portfolio and one advances from the MGCI to a proxy that includes more assets. However, Table 5 shows that the number of assets with superior investment performance levels off as one advances from a US market wealth portfolio (USMI2) to a world market wealth portfolio (ICM). This suggests that little if any incremental benefit arises from using an international orientation. 
TABLE 5

Assets with Significant Jensen Alpha Using the CAPMUI with Risk-free Asset

5\% Level of Significance

\begin{tabular}{|c|c|c|c|c|c|c|c|c|c|c|c|c|}
\hline & \multicolumn{6}{|c|}{ BCT Purformoinc Mrasure (a) } & \multicolumn{6}{|c|}{ Renking on BCT Perfurnatnce Mnasure } \\
\hline & $\$ P 500$ & MCCI & $5 \mathrm{MI}$ & USMII & USMI2 & $10 \mathrm{M}$ & SP500 & MGC & SMl & USMI1 & USMI2 & ICM \\
\hline \multicolumn{13}{|l|}{ ERETT, } \\
\hline EsstCroup & 0.0480 & 0.0438 & 0.0457 & 0.0547 & 0.0457 & 0.0487 & I & 4 & 3 & 1 & 1 & 1 \\
\hline First Union & & 0.0450 & 0.0460 & & 0.0403 & 0.0443 & & 2 & 2 & & 2 & 3 \\
\hline IRT & 0.0302 & 0.0427 & 0.0409 & & 0.0347 & 0.0380 & 4 & 5 & 4 & & 4 & 4 \\
\hline Property Capital & & 0.0406 & & & & & & o & & & & \\
\hline Pennsylvania RET & 0.0410 & 0.0512 & 0.0485 & & 0.0403 & 00454 & 2 & 1 & 1 & & 3 & 2 \\
\hline Wasthington REIT & & 0.0363 & 0.0342 & & & & & 8 & $\therefore$ & & & \\
\hline REIT of California & & 0.0280 & 0.0281 & & & & & 11 & 9 & & & \\
\hline \multicolumn{13}{|l|}{ Common Storis } \\
\hline Beverages -Distillers & & 0.0275 & 0.0246 & & & & & 13 & 11 & & & \\
\hline Conglomerates & & 0.0162 & & & & & & 18 & & & & \\
\hline Containers - Metal & & 00280 & 00260 & & & & & 12 & 10 & & & \\
\hline Containers-Paper & & 0.0372 & 0.0345 & & & 0.0300 & & 7 & 5 & & & 7 \\
\hline Hospital Mgent & & 0.0440 & & & & & & 3 & & & & \\
\hline OA & & 0.0337 & 0.0327 & & 0.0270 & 0.0313 & & 9 & 7 & & 6 & 6 \\
\hline $\begin{array}{l}\text { Publishing } \\
\text { FRC Proprtivs }\end{array}$ & & 0.02 .33 & 0.0204 & & & & & 14 & 14 & & & \\
\hline \multicolumn{11}{|l|}{ FRC Proparties } & & 13 \\
\hline $\begin{array}{l}\text { Apartments } \\
\text { Hotel }\end{array}$ & $\begin{array}{l}0.0107 \\
0.0231\end{array}$ & $\begin{array}{l}0.0118 \\
0.0230\end{array}$ & $\begin{array}{l}0.0117 \\
0.0236\end{array}$ & 0.0110 & 0.0217 & 0.0240 & 5 & 15 & 12 & & 8 & 8 \\
\hline Office-East & 0.0330 & 0.0301 & 0.0310 & 0.0341 & 0.0314 & 0.0317 & 3 & 10 & 8 & 2 & 5 & 5 \\
\hline Retail-West & 0,0005 & 0.0071 & 0.0071 & 0.0076 & 0.0071 & 0.0005 & 12 & 25 & 22 & 10 & 15 & 17 \\
\hline R\&ED Indus:-South & 0.0116 & 0.0116 & 0.0118 & 0.0121 & 0.0119 & 0.0121 & 9 & 21 & 17 & 0 & 11 & 12 \\
\hline R\&D Indus. - East & & 0.0094 & 0.0092 & 0.0100 & 0.0094 & 0.0094 & & 23 & 20 & 9 & 14 & 15 \\
\hline R\&D Indus - West & 0.0190 & 0.0184 & 0.0150 & 0.0218 & 0.0197 & 0.0188 & 7 & 17 & 15 & 4 & 9 & 10 \\
\hline Warehouse - South & 0.0000 & 0.0005 & 0.0066 & 0.0008 & 00005 & 0.0063 & 13 & 26 & 23 & 11 & 17 & 18 \\
\hline Warehouse -East & & 00075 & 0.0073 & & 00067 & 0.0069 & & 24 & 21 & & 16 & 16 \\
\hline Warehouse-West & 0.0140 & 0.0142 & 0.0143 & 0.0149 & 0.0143 & 0.0143 & 8 & 19 & 16 & 5 & 10 & 11 \\
\hline East & 0.0230 & 0.0222 & 0.0226 & 0.0230 & 0.0224 & 0.0229 & 0 & 16 & 13 & 3 & 7 & 9 \\
\hline West & 0.0104 & 0.0105 & 0.0105 & 0.0110 & 0.0106 & 0.0104 & 11 & 22 & 19 & 8 & 13 & 14 \\
\hline
\end{tabular}

Nate: No ACU property has a significant BCT performance $\alpha$ on any market proxy.

TABLE 6

Assets with Significant Jensen Alpha Using the Zero Beta Version of the CAPMUI

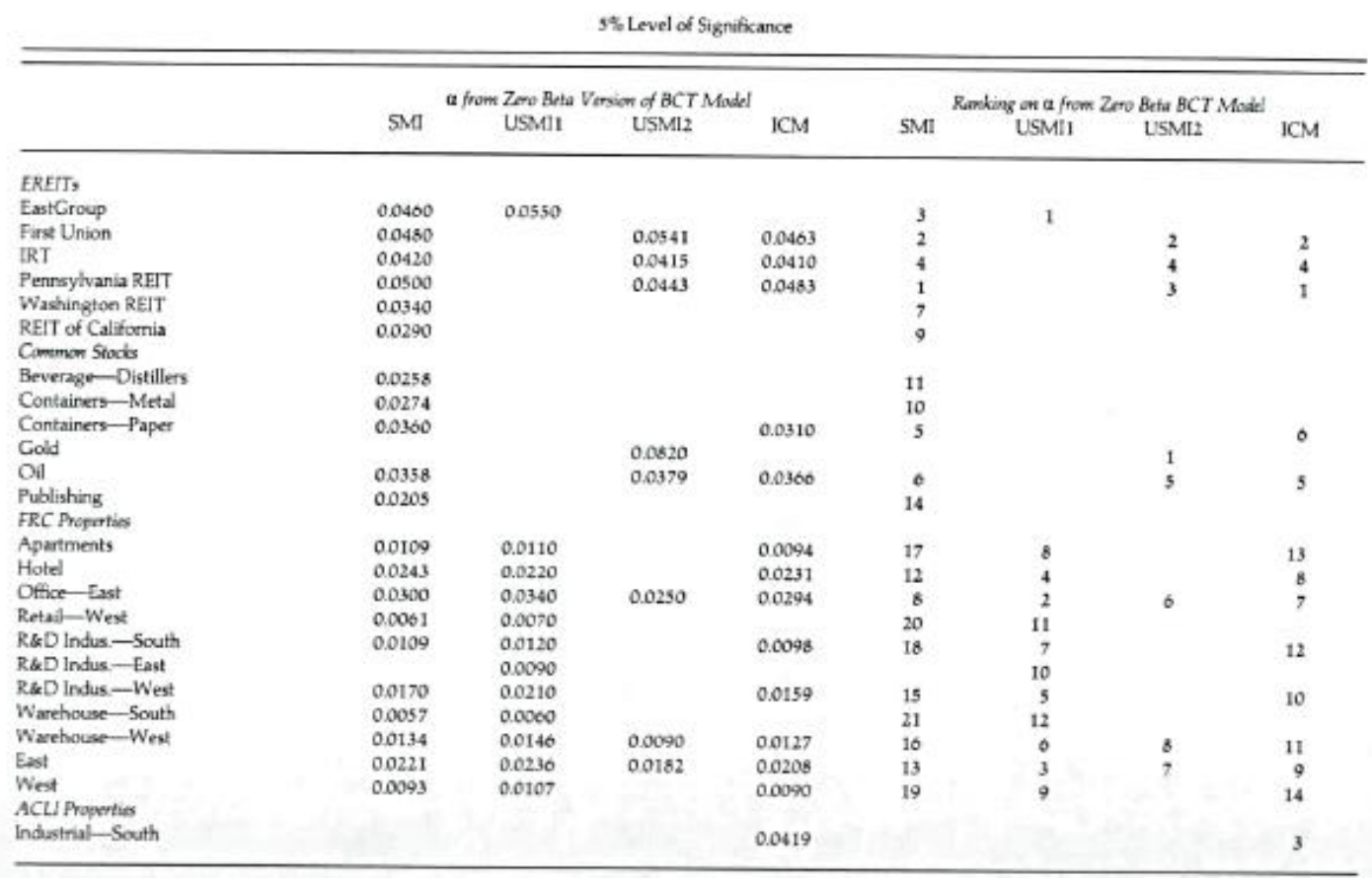

A slightly different perspective of the omitted asset phenomenon is obtained when a zero beta version of the BCT model is utilized. Table 6 shows that the use of a zero beta portfolio in conjunction with the USMI2 leads to a reduction in the number of FRC commercial properties that have positive 
excess returns. The use of a zero beta portfolio thus provides an alternative rationale to the smoothing argument advanced earlier. Even when the zero beta version of the BCT model is used, however, there is some evidence that abnormal returns on commercial real estate are related to smoothing because Table 6, like Table 5, shows that no ACLI property has positive excess returns on any market proxy. In contrast to FRC properties, the use of a zero beta portfolio does not appear to lead to a decrease in the number of equity REITs and common stocks that exhibit superior returns compared to the results when the original version of the BCT model is employed. This suggests that the inclusion of a commercial real estate return series based on imputed sale prices in a market proxy is necessary to price equity REITs in addition to recognizing inflation risk.

Another feature that distinguishes Table 5 from Table 6 is that although the number of assets with superior investment performance decreases as one advances from the SMI benchmark portfolio to a more inclusive market index, the number of FRC properties that have positive excess returns increases when the USMI2 is compared to the ICM. This result obtains in part because real estate represents the major component of the USMI2 but comprises only a minor portion of the ICM.

TABLE 7

Chow Test for Stationarity of Coefficients over the High Inflation and Low Inflation Subperiods

$a$, and $/$ or $\beta_{1}$ and $/$ or $\beta_{n} \neq 0$

$5 \%$ Level of Significance.

\begin{tabular}{|c|c|c|c|c|c|c|c|c|c|c|c|c|c|}
\hline \multicolumn{14}{|l|}{ 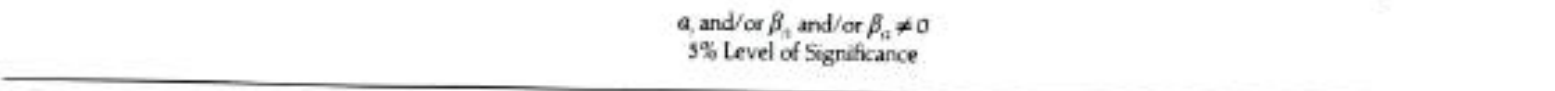 } \\
\hline \multicolumn{14}{|l|}{ L Risk-free Asoef $\mathrm{r}_{\mathrm{r}}$} \\
\hline \multirow[b]{3}{*}{ Asset Class } & \multirow[b]{3}{*}{ Total } & \multicolumn{12}{|c|}{ Market Proxy } \\
\hline & & \multicolumn{2}{|c|}{ SP500 } & \multicolumn{2}{|c|}{$\mathrm{MGCl}$} & \multicolumn{2}{|c|}{$5 \mathrm{MI}$} & \multicolumn{2}{|c|}{ USMII } & \multicolumn{2}{|c|}{ USMI2 } & \multicolumn{2}{|c|}{$\mathrm{ICM}$} \\
\hline & & No. & $\%$ & $\mathrm{No}$. & $\%$ & No. & $\%$ & No. & $\%$ & $\mathrm{Na}$ & $\%$ & No. & $\%$ \\
\hline ERETT & $1 s$ & 0 & $\infty 0$ & 0 & $\mathcal{O O}$ & o & 0.0 & 0 & 0.0 & 0 & 0.0 & 0 & 0.0 \\
\hline STOCKS & 58 & 2 & 3.4 & 2 & 3.4 & 2 & 3.4 & 2 & 3.4 & 2 & 3.4 & 2 & 3.4 \\
\hline FRC & 22 & 4 & 18.2 & 4 & 18.2 & 0 & 27.3 & 4 & 18.2 & 3 & 13.6 & 5 & 22.7 \\
\hline ACU & 9 & 0 & 0.0 & 1 & 11.1 & 1 & I1. 1 & 0 & 0.0 & 1 & 11.1 & 0 & 0.0 \\
\hline & & & & & M & & & & & & & & \\
\hline \multirow[b]{2}{*}{ Asset Class } & \multirow[b]{2}{*}{ Total } & \multicolumn{2}{|c|}{ SMI } & \multicolumn{2}{|c|}{ USMII } & \multicolumn{2}{|c|}{ USML2 } & \multicolumn{2}{|c|}{$\mathrm{ICM}$} & & & & \\
\hline & & $\mathrm{Na}$ & $\%$ & No. & $\%$ & No. & $\%$ & No. & $\%$ & & & & \\
\hline ERETI & 18 & 0 & 0.0 & 0 & $\omega$ & 0 & 0.0 & 0 & 0.0 & & & & \\
\hline STOCKS & 58 & 5 & 8.6 & 2 & 3.4 & 3 & 5.2 & 2 & 3.4 & & & & \\
\hline ERC & 22 & 5 & 22.7 & 4 & 18.2 & 4 & 18.2 & 3 & 13.6 & & & & \\
\hline ACU & 9 & 1 & 11.1 & 0 & 0.0 & 1 & 11.1 & 0 & 0.0 & & & & \\
\hline
\end{tabular}

Logend. Total refers to the total number of assets in each asset class.

No. refers to the number of assets in an asset class that do nof exhibat stationary coefficients.

$\%$ is the percentage of assets in an asset class that do not exhibit stationary coefficients.

Given that superior investment performance exists even after real estate is included in the market proxy and inflation is accounted for, one might ask whether these positive excess returns are 
stationary over different economic environments. Tables 7 and 8 present evidence that investment performance is not stationary over the high and low inflation subperiods even after adjusting for inflation. However, whether the investment performance measure is stationary differs with respect to each asset class. Table 7 indicates that both the original version and the zero beta version of the BCT model are not significantly different under the high inflation and low inflation subperiods for equity REITs and ACLI properties when either the USMI1 or ICM proxy is utilized. This condition also holds when the S\&P 500 is used in conjunction with the standard version of the BCT model. On the other hand, some nonstationarity in the overall models is evident with respect to FRC properties and to a lesser extent common stocks. Table 8 shows that the nonstationarity in the models when FRC properties are evaluated arises mainly from a shift in the BCT performance measure (a) with some shift also occurring in the measure of inflation risk between the economic subperiods. An inspection of this exhibit in conjunction with the computer output reveals that over $40 \%$ of the BCT performance alphas decline as the economic environment changes from high and low inflation. However, this downward shift in alpha does not necessarily imply that superior investment performance for FRC properties is no longer significant. A look at the individual BCT performance measures for FRC properties that have a significant shift in excess returns given a change in the economic environment indicates that offices located in the East as well as the eastern real estate fund exhibit positive investment performance over both subperiods of which version of the BCT model is used.

\section{TABLE 8}

Summary Statistics for Separate T-Tests on Alphas and Betas

$5 \%$ Level of Sigrificance

\begin{tabular}{|c|c|c|c|c|c|c|c|c|c|c|c|c|c|c|}
\hline \multirow[b]{2}{*}{ Asset } & \multirow{2}{*}{$\begin{array}{l}\text { Coeffident } \\
\text { Tested }\end{array}$} & \multirow[b]{2}{*}{ Total } & \multicolumn{2}{|c|}{ SPS00 } & \multicolumn{2}{|c|}{$\begin{array}{l}\text { 1. Risk-frot Asset } \mathrm{r}_{i} \\
\text { MGCl }\end{array}$} & \multicolumn{2}{|c|}{ SMI } & \multicolumn{2}{|c|}{ USMII } & \multicolumn{2}{|c|}{ USMI2 } & \multicolumn{2}{|c|}{$\mathrm{ICM}$} \\
\hline & & & $\mathrm{No}$. & $\%$ & $\mathrm{No}$ & $\%$ & No, & $\%$ & No. & $\%$ & No. & $\%$ & No. & $\%$ \\
\hline \multirow[t]{3}{*}{ EREIT } & $A_{1} \neq 0$ & 18 & 0 & 0 & 0 & 0 & 0 & 0 & 0 & 0 & 0 & 0 & 1 & 5.6 \\
\hline & $B_{1} \neq 0$ & 18 & 1 & 5.6 & 0 & 0 & 0 & 0 & o & 0 & o & 0 & 0 & 0 \\
\hline & $B_{2} \neq 0$ & 18 & 0 & 0 & 1 & 5.6 & 0 & $\mathfrak{o}$ & 0 & $\mathfrak{o}$ & 1 & 5.6 & 0 & 0 \\
\hline \multirow[t]{3}{*}{ STOCKS } & $A_{2} \neq 0$ & 58 & 3 & 5.2 & 5 & 8.6 & 7 & 12.1 & 3 & 5.2 & 4 & 6.9 & 4 & 0.9 \\
\hline & $B_{1} \neq 0$ & 58 & 3 & 5.2 & 3 & 5.2 & 3 & 5.2 & 1 & 1.7 & 4 & 6.9 & 2 & $3 . A$ \\
\hline & $B_{1} \neq 0$ & 58 & 0 & 0 & 1 & 1.7 & 1 & 1.7 & 0 & 0 & 2 & 3.4 & 0 & o \\
\hline \multirow[t]{3}{*}{ FRC } & $A_{1} \neq 0$ & 22 & 10 & 45.5 & 10 & 45.5 & 9 & 40.9 & 9 & 40.9 & to & 45.5 & 9 & 40.9 \\
\hline & $B_{1} \neq 0$ & 22 & 1 & 4.5 & 1 & 4.5 & 0 & 0 & 0 & 0 & 0 & 0 & 0 & 0 \\
\hline & $B_{2} \neq 0$ & 22 & 2 & 9.1 & 2 & 9.1 & 2 & 9.1 & 1 & 4.5 & 1 & 4.5 & 2 & 9.1 \\
\hline \multirow{3}{*}{ ACLI } & $A_{2} \neq 0$ & 9 & 1 & 11.1 & I & 11.1 & 1 & 11.1 & 2 & 22.2 & 2 & 22.2 & 1 & 11.1 \\
\hline & $B_{1} \neq 0$ & 9 & 0 & 0 & 0 & 0 & 0 & 0 & 0 & 0 & 0 & 0 & 0 & $\mathfrak{o}$ \\
\hline & $B_{1} \neq 0$ & 9 & 0 & 0 & 0 & 0 & 0 & 0 & 0 & 0 & 0 & 0 & 0 & 0 \\
\hline
\end{tabular}


TABLE 8 (continued)

Summary Statistics for Separate T-Tests on Alphas and Betas

5\% Level of Sigrificance

\begin{tabular}{|c|c|c|c|c|c|c|c|c|c|c|}
\hline \multirow[b]{2}{*}{ Asset } & \multirow{2}{*}{$\begin{array}{l}\text { Coefficient } \\
\text { Tested }\end{array}$} & \multirow[b]{2}{*}{ Total } & \multicolumn{2}{|c|}{ SMI } & \multicolumn{4}{|c|}{ II. Rist-frer Surnogate $\mathrm{r}_{2}$} & \multicolumn{2}{|c|}{ ICM } \\
\hline & & & No. & $\%$ & No. & $\%$ & No. & $\%$ & No. & $\%$ \\
\hline \multirow[t]{3}{*}{ EREIT } & $A_{1} \neq 0$ & 18 & 0 & 0 & 0 & 0 & 1 & 5.6 & 0 & 0 \\
\hline & $B_{1} \neq 0$ & 18 & 0 & 0 & 0 & 0 & 0 & 0 & 0 & 0 \\
\hline & $B_{1} \neq 0$ & 18 & 0 & 0 & 0 & 0 & 3 & 16.7 & 0 & 0 \\
\hline \multirow[t]{3}{*}{ STOCKS } & $A_{2} \neq 0$ & 58 & 7 & 12.1 & 3 & 5.2 & 3 & 5.2 & 3 & 5.2 \\
\hline & $B, \neq 0$ & 58 & 3 & 5.2 & 1 & 1.7 & 3 & 5.2 & 2 & 3.4 \\
\hline & $B_{1} \neq 0$ & $5 s$ & 2 & 3.4 & 0 & 0 & 2 & 3.4 & 1 & 1.7 \\
\hline \multirow[t]{3}{*}{ FRC } & $A_{2} \neq 0$ & 22 & 9 & 40.9 & 9 & 40.9 & 8 & 36.4 & 10 & 45.5 \\
\hline & $B_{1} \neq 0$ & 22 & 0 & 0 & 0 & 0 & o & $o$ & 0 & o \\
\hline & $B_{i} \neq 0$ & 22 & 2 & 9.1 & 2 & 9.1 & 2 & 9.1 & 0 & 0 \\
\hline \multirow[t]{3}{*}{ ACLI } & $A_{2} \neq 0$ & 9 & 1 & 11.1 & 2 & 22.2 & 2 & 222 & 1 & 11.1 \\
\hline & $B, \neq 0$ & 9 & 0 & 0 & 0 & 0 & 0 & 0 & 0 & 0 \\
\hline & $B_{2} \neq 0$ & 9 & 0 & 0 & 0 & 0 & 1 & 11.1 & 0 & 0 \\
\hline
\end{tabular}

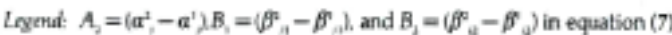

Total refers to the total number of assets in each asset chass.

No. refers to the number of assets in an asset class that do net exhibit stationary coefficients.

To is the percentage of assets in an asset class that do not exhibit stationary coefficients.

\section{Summary and Conclusions}

An issue that this study addresses is whether ranking investment performance is meaningless given that the omission of assets in a market proxy leads to an inaccurate measurement of positive excess returns. This study finds that ranking performance is not necessarily a meaningless exercise because no significant bias exists for the BCT performance measure and the inflation risk estimate, although significant measurement bias corresponds to the estimate of market risk. Next, the study proceeds to examine whether a narrow market proxy such as the S\&P 500 is robust with respect to the evaluation of real estate investment performance given that no significant bias is associated with the BCT performance measure. Fewer assets are found to exhibit superior performance when the S\&P 500 is used as the benchmark portfolio compared to all other proxies except the USMI1. Another issue is whether these positive excess returns are stationary over different economic environments given that superior investment performance exists. The stationarity of the BCT model and the zero beta version of the BCT model over the high and low inflation subperiods is found to differ with respect to each asset class.

A question raised as a consequence of this research is whether the superior investment performance of real estate arises more from the omitted asset phenomenon or from the smoothing bias observed by Hoag [7]. Evidence supporting the smoothing bias proposition is that positive excess returns 
exist when FRC properties are evaluated but not when ACLI properties are analyzed. However, evidence supporting the omitted asset argument is that the inclusion of commercial real estate returns based on imputed sale prices to a market proxy (USMI1) leads to a reduction in the number of equity REITs earning positive excess returns. Further, the inclusion of appraisal-based commercial real estate returns to a market proxy (USMI2) in conjunction with the zero beta version of the BCT model leads to a reduction in the number of FRC properties that have positive excess returns.

\section{Appendix A}

Assets in each general asset category for which performance measures are calculated are as follows:

Equity REITs

California REIT, EastGroup Properties, Federal Realty, First Union, Hollywood Park, Hotel Investors, HRE Properties, Indiana-Florida REIT, IRT, New Plan Realty, Pennsylvania REIT, Property Capital, Property Trust of America, REIT of California, Santa Anita Realty, USP REIT, Washington REIT, and Western Investment.

\section{Common Stock Industry Groups}

Aerospace, Aluminium, Auto Parts-After Market, Auto Parts-Original Equipment, Automobiles, Automobiles^ Trucks, Beverages-Brewers, Beverages-Distillers, Beverages- Soft Drinks, Broadcast Media, Building Materials, Chemicals, Coal, Computers, Conglomerates, Containers-Metal, Containers- Paper, Copper, Cosmetics, Drugs, Electrical Equipment, Electrical-Electronic Majors, Electronics-Instrument, Electronics-Semiconductor, Entertainment, Financial, Foods, Forest Products, Gold Mining, Homebuilding, Hospital Management, Hospital Supplies, Hotel/Motel, Household Appliances, Leisure Time, Machine Tools, Machinery-Industrial, Metals-Miscellaneous, Mobile Homes, Offshore Drilling, Oil Composite, Oil Well Equipment and Services, Paper, Pollution Control, Publishing, Publishing-Newspapers, Restaurants, Retail Stores-Composite, Shoes, Soaps, Steel, Textile Products, Textile- Apparel Manufacturing, Tires and Rubber Goods, Tobacco, Toys, Transportation, and Utilities. 


\section{FRC Commercial Real Estate}

Type: Apartments and Hotel \& Motel. Offices: North, South, East, West. Retail: North, South, East, West. R\&D Industrial: North, South, East, West. Industrial Warehouse: North, South, East, West. ACLI Commercial Real Estate

Retail: South, West. Office: North, South, East, West. Industrial: South, East, West.

\section{Appendix B}

The market values used to construct the portfolio weights for the USMI1 and USMI2 portfolios are obtained as follows:

Cash Equivalents

Values for 3-month Treasury bills, 90-to-119-day commercial paper, and 90-day bankers' acceptances are taken from the Federal Reserve Bulletin.

Corporate Bonds, US Government Bonds and Mortgage-backed Bonds

Aggregate market values for corporate, government and mortgage- backed bonds are obtained from the Shearson-Lehman publication. The Bond Market Annual Report.

Common Stock

Market values associated with the $\mathrm{MGCl}$ index are taken from various issues of Media General Financial Weekly.

Commercial Real Estate

Aggregate value estimates for nonresidential business real estate are taken from Musgrave [15] and subsequent issues of the Survey of Current Business. The series for current dollar net stock of noncorporate nonresidential structures is chosen to avoid double counting corporate real estate. Farm structures are factored out from this total. The aggregate land value is obtained from the Board of Governors of the Federal Reserve System publication Balance Sheets for the US Economy 1945-1986. The mortgage amount outstanding for nonresidential income-producing properties taken from the 
Federal Reserve' Annual Statistical Series is subtracted from the total market value to yield the equity value.

The aggregate value for multifamily residential structures appears in the US Department of Commerce book. Fixed Reproducible Tangible Wealth in the United States 1925-1985. The series utilized is the current dollar net stock of nonfarm five-or-more-unit structures. Aggregate land value for apartments is taken from Balance Sheets for the US Economy 1945-1986. Mortgage debt for apartments contained in the Annual Statistical Series of the Federal Reserve is subtracted from the total multifamily value to obtain the equity apartment estimate. The resulting apartment equity is added to the equity for nonresidential income properties to arrive at the total equity of nonfarm, commercial real estate.

\section{Farm Real Estate}

The market value of farms is taken from Farm Real Estate Market Developments and Agricultural Land Values and Markets. Real estate debt reported in Economic Indicators of the Farm Sector: National Financial Summary 1985 is subtracted from this total value to generate total farm equity. Because aggregate real estate market values are only reported on an annual basis, quarterly figures are calculated through a straight-line interpolation process.

Single Family Homes

The aggregate value of single-family residential structures is taken from the US Department of Commerce publication Fixed Reproducible Tangible Wealth in the United States 1925-1985. The series used is the current dollar net stock of nonfarm one-to-four unit structures. Aggregate residential land values are taken from Balance Sheets for the US Economy 1945-1986. The aggregate home mortgage debt quoted in the Federal Reserve publication Annual Statistical Series is next subtracted from this total value to arrive at single-family home equity. Quarterly market values are obtained from year-end values by linear interpolation.

\section{References}

K. C. Brown and G. D. Brown. Does the Market Portfolio's Composition Matter? Journal of Portfolio Management 13(2): 26-32, 1987.

W. Brueggeman, A. Chen and T. Thibodeau. Real Estate Investment Funds: Performance and Portfolio Considerations. AREUEA Journal 12(3): 333-54, 1984. 
Bureau of Labor Statistics. BLS Handbook of Methods, Volume IL The Consumer Price Index. US Government Printing Office, 1984.

E. F. Fama and G. W. Schwert. Human Capital and Capital Market Equilibrium. Journal of Financial Economics 4(1): 95-125, 1977.

F. Fabozzi and J. C. Francis. Stability Tests for Alphas and Betas over Bull and Bear Market Conditions. Journal of Finance 32(4): 1093-99, 1977.

S. Giliberto. A Note on the Use of Appraisal Data in Indexes of Performance Measurement. AREUEA Journal 16(1): 77-83, 1988.

J. W. Hoag. Towards Indices of Real Estate Value and Return. Journal of Finance 35(2): 569-80, 1980.

R. G. Ibbotson and C. L. Fall. The United States Market Wealth Portfolio. Journal of Portfolio Management 6(1): 82-92, 1979.

R. G. Ibbotson and L. B. Siegel. Real Estate Returns: A Comparison with Other Investments. AREUEA Journal 12(3): 219-42, 1984.

M. C. Jensen. The Performance of Mutual Funds in the Period 1945-1964. Journal of Finance 23(2): 389416, May 1968.

J. Johnston. Econometric Methods. McGraw-Hill, 1984.

S. Kon and F. Jen. Estimation of Time-Varying Systematic Risk and Performance for Mutual Fund Portfolios: An Application of Switching Regression. Journal of Finance 33(2): 457-75, 1978.

C. H. Liu. Market Imperfections, Omitted Asset Markets, and Abnormal Real Estate Returns: A Theoretical and Empirical Investigation. Ph.D. dissertation. University of Texas, Austin, Texas, 1988.

D. Mayers. Non-marketable Assets and Capital Market Equilibrium under Uncertainty. In Michael C. Jensen, editor. Studies in the Theory of Capital Markets. Praeger Publishers, 1972.

J. C. Musgrave. Fixed Capital Stock in the United States: Revised Estimates. Survey of Current Business 61(2): 57-68, 1981.

H. Nourse. The "Cap Rate", 1966-1984: A Test of the Impact of Income Tax Changes on Income Property. Land Economics 63(2): 147-52, 1987.

R. Roll. A Critique of the Asset Pricing Theory's Tests. Journal of Financial Economics 4(2): 129-76, 1977.

K. V. Smith and D. Shulman. The Performance of Equity Real Estate Investment Trusts. Financial Analysis Journal 32(5): 61-66, 1976.

R. F. Stambaugh. On the Exclusion of Assets from Tests of the Two Parameter Model: A Sensitivity Analysis. Journal of Financial Economics 10(3): 237-68, 1982. 
US Department of Commerce. Fixed Reproducible Tangible Wealth in the United States, 1925-1985. US Government Printing Office, 1986. 